\title{
Evaluation of meloxicam for the treatment of obstructive feline idiopathic cystitis
}

Journal of Feline Medicine and Surgery 2016, Vol. 18(11) 925-933 (C) The Author(s) 2015

Reprints and permissions: sagepub.co.uk/journalsPermissions.nav DOI: 10.1177/1098612X15621603 jfms.com

(SAGE

\section{Roswitha Dorsch ${ }^{1}$, Friederike Zellner', Bianka Schulz', Carola Sauter-Louis ${ }^{2}$ and Katrin Hartmann ${ }^{1}$}

\begin{abstract}
Objectives The aim of the study was to investigate the effect of the non-steroidal anti-inflammatory drug meloxicam on the clinical course of obstructive idiopathic cystitis in cats in a placebo-controlled clinical study.

Methods Thirty-seven cats with obstructive idiopathic cystitis were enrolled. Cats received supportive treatment and an indwelling transurethral catheter for $48 \mathrm{~h}$. On days 0 and 1, all cats received buprenorphine $0.01 \mathrm{mg} / \mathrm{kg}$ subcutaneously every $8 \mathrm{~h}$. On day 1 , cats were randomly assigned to the meloxicam $(n=18)$ or placebo group $(n=19)$ and received meloxicam $(0.1 \mathrm{mg} / \mathrm{kg}$ on day $1,0.05 \mathrm{mg} / \mathrm{kg}$ on days $2-5)$ or placebo orally for five consecutive days. Cats were monitored by repeated physical examinations and urinalysis, and with a 5 day questionnaire filled in by the owners after discharge and a telephone interview 3 months after presentation. Parameters for evaluation of treatment success were the occurrence of recurrent urethral obstruction, results of physical examinations and questionnaires.

Results Recurrent urethral obstruction occurred in 4/18 cats (22\%) in the meloxicam group and 5/19 cats (26\%) in the placebo group $(P=1.000)$. General demeanour and pain on abdominal palpation during hospitalisation improved significantly in both groups $(P<0.001)$. After discharge, with regard to general demeanour, food intake and voiding behaviour, there were no significant differences within or between groups at different time points.

Conclusions and relevance Orally administered meloxicam for 5 days did not influence the incidence of recurrent urethral obstruction and the recovery from clinical signs in cats with obstructive feline idiopathic cystitis. The persistence of clinical signs in most of the cats 1 week after initial presentation indicates that symptomatic treatment for a longer period of time is warranted.
\end{abstract}

Accepted: 16 November 2015

\section{Introduction}

Feline lower urinary tract disease (FLUTD) is a common clinical entity in domestic cats, accounting for up to $13 \%$ of cats presented to primary veterinary care. ${ }^{1-3}$ Cats with any disease of the lower urinary tract present with similar clinical signs (dysuria, haematuria, pollakiuria, inappropriate urination), regardless of the aetiology. Very often, no causative aetiology can be identified and after excluding uroliths, bacterial infections and neoplasia, cats are diagnosed with idiopathic FLUTD or feline idiopathic cystitis (FIC). In 55-69\% of cats FIC is responsible for FLUTD. ${ }^{1,4,5}$ Obstructive FLUTD is a feline emergency with an excellent outcome and, with proper care, a survival rate $>90 \% .^{6}$ However, recurrent urethral obstruction (rUO) occurs in up to $58 \%$ of cats, ${ }^{7}$ which is a financial and psychological imposition on the owner and can lead to euthanasia of the cat instead of further medical or surgical treatment. In several studies, the majority of rUO were identified within in the first week of catheter removal. ${ }^{8-10}$

Inflammation is associated with release of substances (eg, eicosanoids, histamines, kinins, serotonin, prostaglandins) that mediate pain perception in the central nervous system (CNS) via stimulation of nociceptors

\footnotetext{
${ }^{1}$ Clinic of Small Animal Medicine, LMU University Munich, Munich, Germany

${ }^{2}$ Clinic for Ruminants, LMU University Munich, Munich, Germany
}

\section{Corresponding author:}

Roswitha Dorsch Dr med vet, Dipl ECVIM-CA, Clinic of Small Animal Medicine, LMU University Munich, 80539 Munich, Germany

Email: r.dorsch@medizinische-kleintierklinik.de 
and conduction via afferent fibres. Increased numbers of mast cells have been identified in cats with idiopathic cystitis and are thought to be involved in the pathogenesis. ${ }^{11}$ The effect of inflammatory doses of prednisolone on the course of disease has been investigated in a prospective study, but no difference in response has been seen between cats treated with prednisolone and cats treated with placebo. ${ }^{12}$ Non-steroidal anti-inflammatory drugs (NSAIDs) are widely used by veterinarians for this disease. A beneficial effect has not been identified in two retrospective studies including cats with nonobstructive FIC and obstructive FIC, respectively. ${ }^{13,14}$ However, the effect of NSAIDs has not yet been evaluated in a prospective trial.

NSAIDs inhibit the activity of cyclooxygenases (COX) and decrease the synthesis of prostaglandins. Meloxicam is an NSAID of the oxicam group with weak selectivity for COX-2. COX-1 is the predominantly constitutively produced enzyme that is present in almost all body tissues, whereas COX-2 is predominantly inducible and highly upregulated in areas of inflammation, ${ }^{15}$ and constitutively produced along with COX- 1 in the CNS, the kidney, vascular endothelium, reproductive tract and gastrointestinal tract. ${ }^{16-18}$ Therefore, the anti-inflammatory and analgesic effect could, theoretically, be beneficial in cats suffering from FIC.

The aim of this prospective, placebo-controlled study was to evaluate the effect of meloxicam on the incidence of rUO and on the clinical course of the disease in cats with obstructive FIC.

\section{Materials and methods}

\section{Study design}

The study had a prospective, double-blind, placebo-controlled randomised design and included 37 cats with obstructive FIC. Initially, cats with either non-obstructive $(n=13)$ or obstructive $(n=37)$ FIC were included in the study. As the majority of cats suffered from obstructive FIC, only cats with obstructive FIC were evaluated, to create a more uniform study population. The study medication (meloxicam and placebo) was provided by the manufacturer in identical-looking numbered bottles in a liquid formulation. The placebo and meloxicam looked identical and were indistinguishable. Cats enrolled into the study were sequentially numbered and received the medication with the same number. All cats were treated at the Clinic of Small Animal Medicine, LMU, Munich, from November 2006 to August 2008. The study was conducted according to German animal welfare law. Informed owner consent was obtained from all owners before inclusion of cats into the study.

\section{Patients}

Cats with clinical signs of FLUTD, such as stranguria, haematuria, pollakiuria or painful voiding, and a diagnosis of FIC were included in the study. Urethral obstruction was assumed if cats had a history of unsuccessful attempts to void and a large, tense and painful urinary bladder on abdominal palpation. To properly classify the cats as having FIC, urinalysis, including urine specific gravity (USG), dipstick, urine sediment and urine culture, was performed along with abdominal radiographs and ultrasound of the urinary tract to identify urolithiasis and evidence of neoplasia, which led to exclusion from the study. All cats were tested for feline immunodeficiency virus and feline leukaemia virus, and a total thyroxine was measured in all cats older than 8 years. Cats were also excluded if other diseases, such as diabetes mellitus or hyperthyroidism, were identified, or if they had been treated with steroids, antimicrobial drugs, or NSAIDs in the 2 weeks before presentation. Cats were retrospectively withdrawn from the study if they had a positive urine culture.

Urinalyses were performed on presentation, 48-60 h after presentation and at the recheck examination 14-21 days later. Urine samples were collected by transcutaneous cystocentesis. A hand refractometer (Atago) was used to determine USG. The urine was then analysed with reagent strips (Combur-9; Roche Diagnostics). After centrifugation at $2000 \mathrm{rpm}(672 \mathrm{~g})$ for 5 mins, the urine sediment was examined microscopically. The number of red blood cells (RBC) per high power field (HPF) and white blood cells (WBC)/HPF were categorised as follows: RBC/HPF $(<10,10-24,25-100,>100)$, WBCs $/$ HPF $(0-3,4-6,7-19,20-50,>50)$.

\section{Initial treatment}

On admission (day 0), intravenous (IV) fluid therapy with a low potassium volume replacement solution (Lactated Ringer's solution) was started. All of the cats received IV fluids and buprenorphine and as soon as they were clinically stable, an indwelling urinary catheter (silicon feeding tube, $\mathrm{CH} 4.5,1.0 \times 1.5 \mathrm{~mm}$; Braun) was inserted aseptically under anaesthesia. Administered type and volume of IV fluid therapy was adjusted based on the degree of dehydration, plasma electrolyte concentrations, and the severity of postobstructive diuresis. All cats received 0.010 $\mathrm{mg} / \mathrm{kg}$ buprenorphine (Temgesic; Essex Pharma GmbH) at the time of admission and every $8 \mathrm{~h}$ subcutaneously for a period of 2 days. In cats that presented with postrenal azotaemia, metabolic acidosis or hyperkalaemia, serum chemistry and blood gas analysis were repeated after $24 \mathrm{~h}$ before starting study medication (day 1 ).

After 36-48 h (day 2), the transurethral catheter was removed. Before removal, a urine sample for routine analysis and for aerobic bacterial culture was taken. The cats were watched for their voiding behaviour afterwards and remained hospitalised until they were able to void spontaneously for $24 \mathrm{~h}$. If cats showed attempts to urinate but these attempts were unsuccessful despite an 
enlarged urinary bladder, cats were assumed to suffer from rUO.

\section{Study medication}

Meloxicam or placebo was started $24 \mathrm{~h}$ after presentation. The $24 \mathrm{~h}$ window was planned for re-establishment of urine flow and to ensure that cats had a clinically normal volume and hydration status before entry into the study. In bottles that contained meloxicam the concentration of the drug was $0.5 \mathrm{mg} / \mathrm{ml}$. The dose of oral meloxicam was $0.1 \mathrm{mg} / \mathrm{kg}$ on day 1 and $0.05 \mathrm{mg} / \mathrm{kg}$ on the following 4 days (day 2-day 5). Therefore, all cats received $0.2 \mathrm{ml} / \mathrm{kg}$ of the suspension on day 1 and 0.1 $\mathrm{ml} / \mathrm{kg}$ of the suspension on day 2 to day 5 . At the time of discharge from the hospital, owners were given written instructions to complete the 5 day treatment course with the study medication. The code was broken once in the middle of the study (after 24 cats) and in addition at the end of the study for the remaining cats.

\section{Assessment of treatment success}

The main parameter for treatment success was the occurrence of rUO within the first 7 days. Cats with rUO were censored at the time of rUO and excluded from further analysis. Results of the daily physical examinations (body temperature, respiratory rate, heart rate, abdominal pain, body weight, general demeanour, food intake, voiding behaviour and body weight) during hospitalisation and on recheck examination scheduled 10-14 days after discharge were recorded. General demeanour was assessed as normal or reduced (calm, depressed, aggressive or defensive); pain on abdominal palpation was categorised as follows: clearly painful (tensed abdomen or displaying defence movements or vocalising upon abdominal palpation), mildly painful (discomfort on abdominal palpation, mild or moderately tensed abdomen) or not painful. Food intake was assessed as normal, reduced or anorexia.

On discharge from the hospital, owners were given a questionnaire for the assessment of the health status, voiding behaviour and macroscopic haematuria of their cats for the following 5 days. Owners graded the general condition, voiding behaviour (frequency, duration, presence of pain) and food intake of the cats on a $10 \mathrm{~cm}$ visual analogue scale. The left end of the scale was marked with findings expected in a normal cat, such as normal food intake and no straining to urinate, whereas the right end of the scale was marked with abnormal findings such as no food intake, severe straining to urinate, frequently voiding outside the litter box. The distances from the left end of the scale to the marking were measured. Therefore, lower numbers indicated a more positive condition of the evaluated cat. A telephone interview was performed 3 months after initial presentation to see if cats had experienced recurrent episodes.
In addition, results of urinalyses performed on day 0 , day 2 or day 3 and on recheck examination 10-14 days after discharge were evaluated.

\section{Statistical analysis}

Prism 5.04 software (GraphPad) was used for the statistical analysis. The Mann-Whitney U-test was used to evaluate differences in age and body weight between groups on presentation. The Kruskal-Wallis test and Dunn's multiple comparison tests were used to evaluate for differences in the continuous parameters between groups at different time points and within groups between different time points. Results were regarded as significant if $P<0.05$. For investigation of categorical parameters (previous episodes of FLUTD, general demeanour, food intake, pain on abdominal palpation, macroscopic urine appearance, the degree of proteinuria, the numbers of erythrocytes and leukocytes in the urine) between cats treated with meloxicam and cats treated with placebo, the $\chi^{2}$ test was performed.

\section{Results}

Cats and laboratory results on admission

Thirty-seven male cats with obstructive FIC were included in the study. There were no statistically significant differences between the treatment group and placebo group regarding age and body weight (Table 1). Cats in the meloxicam group had suffered from a significantly higher number of previous FLUTD episodes than cats of the placebo group $(P=0.046)$ and the proportion of cats with macroscopic haematuria was significantly higher in the meloxicam group $(P=0.049)$. However, at the time treatment was started (day 1) equal numbers of cats in both treatment groups had macroscopic haematuria (Table 2). Analysis of haematology, serum chemistry, venous blood gas and urine revealed a significantly lower ionised calcium $(P=0.040)$ in cats in the placebo group compared with cats in the meloxicam group on day 0 (Table 3 ). Urinalysis results revealed no significant differences between treatment groups at any time point (Table 4).

\section{Evaluation of treatment success}

Upon removal of the urinary catheter after $36-48 \mathrm{~h}$, nine cats (four $[22.2 \%$ ] in the meloxicam group, five [26.3\%] in the placebo group) suffered from rUO within the first week. Six rUOs (three cats from each group) were observed on day 2 and three (one meloxicam, two placebo) on day $3(P=1.000)$. Two more cats in the meloxicam group had rUO on day 21 and day 79, and one cat in the placebo group on day 32. Cats in the meloxicam and placebo groups were presented for a recheck examination after a mean \pm SD of $17.4 \pm 5.14$ and $18.8 \pm 4.33$ days, respectively $(P=0.499)$. Results of physical examination findings are illustrated in Tables 2 and 5 . There were no significant differences between treatment groups at any 
Table 1 Signalment and history of 37 male cats with obstructive feline idiopathic cystitis

\begin{tabular}{|c|c|c|c|c|}
\hline & & Meloxicam $(n=18)$ & Placebo $(n=19)$ & $P$ value \\
\hline \multirow[t]{2}{*}{ Breed } & DSH & 13 & 14 & 1.000 \\
\hline & Non-DSH & $5^{\star}$ & $5^{\dagger}$ & \\
\hline \multirow[t]{3}{*}{ Episodes } & First episode & 10 & 14 & \\
\hline & Second episode & 3 & 5 & 0.046 \\
\hline & $\geqslant 3$ episodes & 5 & 0 & \\
\hline Mean \pm SD age (years) & & $5.6 \pm 2.23$ & $6.1 \pm 2.14$ & 0.587 \\
\hline Median (range) age (years) & & $5.5(2-11)$ & $6.0(1-13)$ & \\
\hline Mean \pm SD BM (kg) & & $6.2 \pm 1.41$ & $5.6 \pm 1.05$ & 0.135 \\
\hline Median (range) BM (kg) & & $6.3(3.0-8.9)$ & $5.5(4.2-7.7)$ & \\
\hline
\end{tabular}

*One Persian, two Angora, one Maine Coon, one Norwegian Forest Cat mix

tOne Persian, one Persian mix, one Siamese mix, one Chartreux mix, one Norwegian Forest Cat

$\mathrm{DSH}=$ domestic shorthair; $\mathrm{BM}=$ body mass

$P<0.05$ was considered significant (bold)

Table 2 Evaluation of 37 male cats with obstructive idiopathic cystitis during hospitalisation and at recheck examination $(\mathrm{RC})$. Cats with recurrent urethral obstruction were censored at the time of recurrent urethral obstruction

\begin{tabular}{|c|c|c|c|c|c|c|c|}
\hline & Day & & $\begin{array}{l}\text { Meloxicam } \\
\mathrm{n}\end{array}$ & $\begin{array}{l}\text { Placebo } \\
n\end{array}$ & $\begin{array}{l}P \text { value } \\
\text { meloxicam } \\
\text { vs placebo }\end{array}$ & $\begin{array}{l}P \text { value } \\
\text { meloxicam day } 1 \\
\text { vs } 2,3 \text { and RC }\end{array}$ & $\begin{array}{l}P \text { value placebo } \\
\text { day } 1 \text { vs } 2,3 \\
\text { and } R C\end{array}$ \\
\hline \multirow{10}{*}{$\begin{array}{l}\text { General } \\
\text { demeanour }\end{array}$} & \multirow{2}{*}{0} & Normal & 6 & 5 & \multirow{2}{*}{0.728} & & \\
\hline & & Reduced & 12 & 14 & & & \\
\hline & \multirow[t]{2}{*}{1} & Normal & 15 & 14 & \multirow[t]{2}{*}{0.693} & & \\
\hline & & Reduced & 3 & 5 & & & \\
\hline & \multirow[t]{2}{*}{2} & Normal & 16 & 16 & \multirow[t]{2}{*}{1.000} & \multirow[t]{2}{*}{1.000} & \multirow[t]{2}{*}{0.693} \\
\hline & & Reduced & 2 & 3 & & & \\
\hline & \multirow[t]{2}{*}{3} & Normal & 14 & 14 & \multirow[t]{2}{*}{ NA } & \multirow[t]{2}{*}{0.238} & \multirow[t]{2}{*}{0.057} \\
\hline & & Reduced & 0 & 0 & & & \\
\hline & \multirow[t]{2}{*}{$\mathrm{RC}$} & Normal & 12 & 13 & \multirow[t]{2}{*}{ NA } & \multirow[t]{2}{*}{0.255} & \multirow[t]{2}{*}{0.064} \\
\hline & & Reduced & 0 & 0 & & & \\
\hline \multirow{15}{*}{$\begin{array}{l}\text { Abdominal } \\
\text { palpation }\end{array}$} & \multirow[t]{3}{*}{0} & Clearly painful & 11 & 13 & \multirow[t]{3}{*}{0.819} & & \\
\hline & & Moderately painful & 2 & 3 & & & \\
\hline & & Not painful & 4 & 3 & & & \\
\hline & \multirow[t]{3}{*}{1} & Clearly painful & 4 & 5 & \multirow[t]{3}{*}{0.450} & & \\
\hline & & Moderately painful & 5 & 2 & & & \\
\hline & & Not painful & 9 & 11 & & & \\
\hline & \multirow[t]{3}{*}{2} & Clearly painful & 5 & 6 & \multirow[t]{3}{*}{0.720} & \multirow[t]{3}{*}{0.847} & \multirow[t]{3}{*}{0.692} \\
\hline & & Moderately painful & 5 & 3 & & & \\
\hline & & Not painful & 7 & 8 & & & \\
\hline & \multirow[t]{3}{*}{3} & Clearly painful & 2 & 2 & \multirow[t]{3}{*}{0.632} & \multirow[t]{3}{*}{0.893} & 0.706 \\
\hline & & Moderately painful & 4 & 2 & & & \\
\hline & & Not painful & 7 & 9 & & & \\
\hline & $\mathrm{RC}$ & Clearly painful & 0 & 1 & NA & 0.019 & NA \\
\hline & & Moderately painful & 0 & 0 & & & \\
\hline & & Not painful & 11 & 10 & & & \\
\hline Food intake & 0 & Normal & 6 & 4 & 0.235 & & \\
\hline & & Reduced & 9 & 7 & & & \\
\hline & & Anorexia & 3 & 8 & & & \\
\hline & 1 & Normal & 3 & 4 & 0.878 & & \\
\hline & & Reduced & 10 & 9 & & & \\
\hline & & Anorexia & 5 & 6 & & & \\
\hline
\end{tabular}


Table 2 (Continued)

\begin{tabular}{|c|c|c|c|c|c|c|c|}
\hline & \multicolumn{2}{|c|}{ Day } & \multirow{2}{*}{$\begin{array}{l}\text { Meloxicam } \\
\text { n } \\
3\end{array}$} & \multirow{2}{*}{$\begin{array}{l}\text { Placebo } \\
\text { n } \\
6\end{array}$} & \multirow{2}{*}{$\begin{array}{l}\text { Pvalue } \\
\text { meloxicam } \\
\text { vs placebo } \\
0.539\end{array}$} & \multirow{2}{*}{$\begin{array}{l}P \text { value } \\
\text { meloxicam day } 1 \\
\text { vs } 2,3 \text { and } R C \\
0.771\end{array}$} & \multirow{2}{*}{$\begin{array}{l}P \text { value placebo } \\
\text { day } 1 \text { vs } 2,3 \\
\text { and } R C \\
0.670\end{array}$} \\
\hline & 2 & Normal & & & & & \\
\hline & & Reduced & 11 & 9 & & & \\
\hline & & Anorexia & 3 & 4 & & & \\
\hline & 3 & Normal & 2 & 5 & 0.404 & 0.606 & 0.440 \\
\hline & & Reduced & 10 & 7 & & & \\
\hline & & Anorexia & 2 & 2 & & & \\
\hline & $\mathrm{RC}$ & Normal & 10 & 12 & NA & $<0.001$ & $<0.001$ \\
\hline & & Reduced & 0 & 1 & & & \\
\hline & & Anorexia & 2 & 0 & & & \\
\hline \multirow{5}{*}{$\begin{array}{l}\text { Macroscopic } \\
\text { haematuria }\end{array}$} & 0 & & $13 / 18$ & $7 / 19$ & 0.049 & & \\
\hline & 1 & & $12 / 18$ & $12 / 19$ & 1.000 & & \\
\hline & 2 & & $9 / 18$ & $11 / 18$ & 0.738 & 0.500 & 1.000 \\
\hline & 3 & & $5 / 14$ & $3 / 12$ & 0.683 & 0.153 & 0.066 \\
\hline & $\mathrm{RC}$ & & $0 / 12$ & $1 / 11$ & 0.478 & $<0.001$ & 0.007 \\
\hline
\end{tabular}

The $\chi^{2}$ test was used for comparison of results between treatment groups at individual time points and between time points within groups $P<0.05$ was considered significant (bold)

$\mathrm{NA}=$ not applicable

Table 3 Results of haematology, serum chemistry and venous blood gas from 37 male cats with obstructive feline idiopathic cystitis on day 0 (day of admission)

\begin{tabular}{lccc} 
& Meloxicam & Placebo & $P$ value \\
\hline Erythrocytes $\left(\times 10^{9} / \mathrm{l}\right)$ & $10.24 \pm 1.14$ & $9.91 \pm 1.47$ & 0.450 \\
Haematocrit $(\mathrm{I} / \mathrm{l})$ & $0.43 \pm 0.04$ & $0.41 \pm 0.06$ & 0.306 \\
Leukocytes $\left(\times 10^{6} / \mathrm{l}\right)$ & $11.86 \pm 4.75$ & $13.62 \pm 5.00$ & 0.636 \\
Creatinine $(\mu \mathrm{mol} / \mathrm{l})$ & $244.20 \pm 160.40$ & $412.10 \pm 466.70$ & 0.438 \\
Urea $(\mathrm{mmol} / \mathrm{l})$ & $17.49 \pm 8.79$ & $24.04 \pm 22.64$ & 0.704 \\
Glucose $(\mathrm{mmol} / \mathrm{l})$ & $10.39 \pm 2.84$ & $8.41 \pm 2.32$ & 0.053 \\
Bilirubin $(\mu \mathrm{mol} / \mathrm{l})$ & $2.34 \pm 1.20$ & $2.55 \pm 2.35$ & 0.586 \\
Alkaline phosphatase $(\mathrm{U} / \mathrm{l})$ & $31.00 \pm 10.25$ & $28.00 \pm 11.28$ & 0.425 \\
Alanine aminotransferase $(\mathrm{U} / \mathrm{l})$ & $62.41 \pm 18.89$ & $77.89 \pm 46.50$ & 0.314 \\
pH & $7.28 \pm 0.07$ & $7.25 \pm 0.12$ & 0.673 \\
Bicarbonate $(\mathrm{mmol} / \mathrm{l})$ & $17.86 \pm 2.31$ & $17.13 \pm 3.86$ & 0.356 \\
pCO $(\mathrm{mmHg})$ & $40.06 \pm 7.30$ & $38.68 \pm 5.85$ & 0.737 \\
Potassium $(\mathrm{mmol} / \mathrm{l})$ & $3.97 \pm 0.62$ & $4.91 \pm 1.94$ & 0.301 \\
lonised calcium $(\mathrm{mmol} / \mathrm{l})$ & $1.22 \pm 0.07$ & $1.10 \pm 0.21$ & $\mathbf{0 . 0 4 0}$ \\
Phosphate $(\mathrm{mmol} / \mathrm{l})$ & $1.63 \pm 0.31$ & $2.04 \pm 1.19$ & 0.909 \\
Sodium $(\mathrm{mmol} / \mathrm{l})$ & $150.10 \pm 3.43$ & $147.50 \pm 5.38$ & 0.070 \\
Chloride $(\mathrm{mmol} / \mathrm{l})$ & $116.30 \pm 4.03$ & $112.10 \pm 10.83$ & 0.595
\end{tabular}

Data are mean $\pm \mathrm{SD}$

$P<0.05$ was considered significant (bold)

time point. Significantly improved food intake was reported at the time of recheck examination compared with day 1 in both treatment groups. The proportion of cats with macroscopic haematuria was significantly lower on recheck examination than on day 1 in both groups. No significant differences in general demeanour and pain on abdominal palpation within groups between day 1 , day 2, day 3 were identified. However, there was a significant difference in pain on abdominal palpation in the meloxicam group between day 1 and the recheck examination $(P=0.019)$.

Regarding the results of the urinalysis, proteinuria and haematuria significantly improved during the study period. USG was significantly lower on day 2 or 3 than on day 0 and on recheck examination in both treatment groups (all $P<0.05$ ) (Table 5).

Questionnaires for all 14 cats in the meloxicam group and $13 / 14$ cats in the placebo group without rUO were 
Table 4 Urinalysis results of 37 male cats treated with meloxicam and placebo on day 0 and day 2 or 3 and on recheck examination $(\mathrm{RC})$

\begin{tabular}{|c|c|c|c|c|c|c|}
\hline & Day & Meloxicam & Placebo & $P$ value & $\begin{array}{l}P \text { value meloxicam } \\
\text { day } 0 \text { vs } 2 \text { or } 3 \text { and } \\
\text { RC }\end{array}$ & $\begin{array}{l}P \text { value placebo } \\
\text { day } 0 \text { vs } 2 \text { or } 3 \\
\text { and } R C\end{array}$ \\
\hline \multirow[t]{3}{*}{ Protein ${ }^{\star}$} & 0 & $\begin{array}{l}+++ \\
(+ \text { to }+++)\end{array}$ & $\begin{array}{l}+++ \\
\text { (negative to } \\
+++ \text { ) }\end{array}$ & 0.449 & & \\
\hline & 2 or 3 & $\stackrel{+}{\text { (negative to }+++ \text { ) }}$ & $\begin{array}{l}+ \\
\text { (negative to } \\
+++ \text { ) }\end{array}$ & 0.781 & 0.003 & 0.035 \\
\hline & $\mathrm{RC}$ & $\begin{array}{l}+ \\
(+ \text { to }+++)\end{array}$ & $\begin{array}{l}+ \\
(+ \text { to }++)\end{array}$ & 0.490 & 0.005 & 0.004 \\
\hline \multirow[t]{3}{*}{$\mathrm{RBC} / \mathrm{HPF}$} & 0 & $\begin{array}{l}>100 / \mathrm{HPF} \\
(0-24 \text { to }>100 / \mathrm{HPF})\end{array}$ & $\begin{array}{l}>100 / \mathrm{HPF} \\
(0-24 \text { to }> \\
100 / \mathrm{HPF})\end{array}$ & 0.231 & & \\
\hline & 2 or 3 & $\begin{array}{l}25-100 \\
(0-24 \text { to }>100 / H P F)\end{array}$ & $\begin{array}{l}25-100 \\
(0-24 \text { to }> \\
100 / \mathrm{HPF})\end{array}$ & 0.449 & NA & 0.113 \\
\hline & $\mathrm{RC}$ & $\begin{array}{l}<24 / \mathrm{HPF} \\
(0-24 \text { to }>100 / \mathrm{HPF})\end{array}$ & $\begin{array}{l}<24 / \mathrm{HPF} \\
(0-24 \text { to }> \\
100 / \mathrm{HPF})\end{array}$ & 0.766 & 0.003 & 0.028 \\
\hline \multirow[t]{3}{*}{ WBC/HPF } & 0 & $\begin{array}{l}0-3 \\
(0-3 \text { to }>50 / H P F)\end{array}$ & & 0.441 & & \\
\hline & 2 or 3 & $\begin{array}{l}4-6 \\
(0-3 \text { to }>50 / H P F)\end{array}$ & & NA & 0.758 & 0.081 \\
\hline & $\mathrm{RC}$ & $\begin{array}{l}0-3 \\
\text { (0-3 to 20-50/HPF) }\end{array}$ & & NA & 0.440 & 0.081 \\
\hline \multirow[t]{3}{*}{$\mathrm{USG}^{+}$} & 0 & $1.040(1.018-1.048)$ & $\begin{array}{l}1.033 \\
(1.006-1.045)\end{array}$ & NS & & \\
\hline & 2 or 3 & $1.011(1.005-1.046)$ & $\begin{array}{l}1.011 \\
(1.006-1.045)\end{array}$ & NS & $<0.05$ & $<0.05$ \\
\hline & $\mathrm{RC}$ & $\begin{array}{l}1.041 \\
(1.012-1.051)\end{array}$ & $\begin{array}{l}1.044 \\
(1.020-1.055)\end{array}$ & NS & NS & NS \\
\hline
\end{tabular}

Data are median (range). $\chi^{2}$ tests were used for investigation of categorical parameters (macroscopic haematuria, proteinuria, red blood cells $[\mathrm{RBC}] /$ high power field [HPF] and white blood cells [WBC]/HPF). For analysis of the urine specific gravity (USG) a Kruskal-Wallis test and Dunn's multiple comparison tests were performed. $P<0.05$ was considered significant (bold)

*Protein analysed by dipstick analysis

+USG was determined by a hand refractometer

$N A=$ not applicable; NS = not significant

available for analysis (Table 6). No significant differences between or within groups between time points were identified. The score means for all evaluated parameters were in the lower third of the scale for all parameters. After 5 days at home, however, none of the cats in both groups had a normal general demeanour or a normal food intake. Pollakiuria had completely resolved in three and four cats of the meloxicam and placebo group, respectively. Owners assessed five cats of the meloxicam group and seven cats of the placebo groups as still painful on voiding. Only three cats in the meloxicam group and one cat in the placebo group did not show any of the clinical sings pollakiuria, stranguria, painful voiding or periuria 5 days after discharge.
Four cats of each group had a culture-positive urine sample on day 2 with growth of $\geqslant 10^{3}$ colony-forming units $/ \mathrm{ml}$ of a single organism. None of the cats with rUO had a positive culture at the time of urinary catheter removal on day 2.

\section{Discussion}

The present study investigated the use of meloxicam in a population of cats with obstructive FIC. The use of the antiinflammatory and analgesic drug meloxicam did not influence the incidence of rUO early after catheter removal and the severity of clinical signs in the present study. The recurrence rate within the first 7 days was $22.2 \%$ in the meloxicam group and $26.3 \%$ in the placebo group, and the overall recurrence rate within 3 months was $33.3 \%$ and $31.5 \%$, 
Table 5 Physical examination findings for 37 male cats with obstructive idiopathic cystitis during hospitalisation and at recheck examination $(\mathrm{RC})$

\begin{tabular}{|c|c|c|c|c|c|c|}
\hline & Day & Meloxicam & Placebo & $\begin{array}{l}P \text { value } \\
\text { meloxicam vs } \\
\text { placebo }\end{array}$ & $\begin{array}{l}P \text { value meloxicam } \\
\text { day } 1 \text { vs } 2,3 \text { and } \\
\text { RC }\end{array}$ & $\begin{array}{l}P \text { value placebo } \\
\text { day } 1 \text { vs } 2,3 \text { and } \\
\text { RC }\end{array}$ \\
\hline \multirow[t]{5}{*}{ Temperature $\left({ }^{\circ} \mathrm{C}\right)$} & 0 & $38.47 \pm 0.67$ & $38.13 \pm 0.86$ & NS & & \\
\hline & 1 & $38.85 \pm 0.70$ & $38.77 \pm 0.41$ & NS & & \\
\hline & 2 & $38.96 \pm 0.47$ & $38.66 \pm 0.39$ & NS & NS & NS \\
\hline & 3 & $39.11 \pm 0.52$ & $38.80 \pm 0.54$ & NS & NS & NS \\
\hline & $\mathrm{RC}$ & $38.67 \pm 0.31$ & $38.34 \pm 0.44$ & NS & NS & NS \\
\hline \multirow[t]{5}{*}{ Heart rate/min } & 0 & $181.20 \pm 31.55$ & $170.20 \pm 32.96$ & NS & & \\
\hline & 1 & $200.40 \pm 29.95$ & $188.30 \pm 33.58$ & NS & & \\
\hline & 2 & $196.60 \pm 24.96$ & $178.90 \pm 32.17$ & NS & NS & NS \\
\hline & 3 & $195.60 \pm 26.90$ & $193.10 \pm 23.29$ & NS & NS & NS \\
\hline & $\mathrm{RC}$ & $191.10 \pm 17.38$ & $190.80 \pm 29.64$ & NS & NS & NS \\
\hline \multirow{5}{*}{$\begin{array}{l}\text { Respiratory } \\
\text { rate/min }\end{array}$} & 0 & $55.41 \pm 24.83$ & $37.21 \pm 15.85$ & & & \\
\hline & 1 & $53.60 \pm 32.37$ & $40.00 \pm 10.43$ & NS & & \\
\hline & 2 & $42.60 \pm 14.77$ & $40.82 \pm 9.65$ & NS & NS & NS \\
\hline & 3 & $46.22 \pm 13.32$ & $42.90 \pm 13.03$ & NS & NS & NS \\
\hline & $\mathrm{RC}$ & $61.75 \pm 26.99$ & $57.50 \pm 34.87$ & NS & NS & NS \\
\hline \multirow[t]{5}{*}{ Body weight (kg) } & 0 & $6.24 \pm 1.41$ & $5.62 \pm 1.05$ & NS & & \\
\hline & 1 & $6.24 \pm 1.411$ & $5.62 \pm 1.02$ & NS & & \\
\hline & 2 & $6.24 \pm 1.380$ & $5.61 \pm 1.04$ & NS & NS & NS \\
\hline & 3 & $5.86 \pm 1.27$ & $5.44 \pm 1.08$ & NS & NS & NS \\
\hline & $\mathrm{RC}$ & $5.98 \pm 1.32$ & $5.12 \pm 0.93$ & NS & NS & NS \\
\hline
\end{tabular}

Data are mean $\pm \mathrm{SD}$. Cats with recurrent urethral obstruction were censored at the time of recurrent urethral obstruction. For comparison of parameters between groups at individual time points and between time points within groups the Kruskall-Wallis test and a Dunn's multiple comparison test were performed. $P<0.05$ was considered significant NS = not significant

respectively. This is lower than previously reported in a prospective study that evaluated the effect of intravesically administered buffered lidocaine with $58 \%$ of cats suffering from $\mathrm{rUO}, 7$ and higher than in three retrospective studies with recurrence rates of $16 \%, 22 \%$ and $24 \%$ up to 6 months after discharge from the hospital, $, 10,14$ and two prospective studies that investigated the effect of intravesically administered glycosaminoglycans in cats with obstructive FIC, with recurrence rates of $18 \%$ and $19 \% .{ }^{19,20}$ A longer duration of catheterisation (mean duration $32.1 \mathrm{~h}$ vs $21.6 \mathrm{~h}$ ), the use of a smaller urinary catheter and the use of prazosin compared with phenoxybenzamine were associated with lower rates of rUO. ${ }^{10,14}$ In the present study, the indwelling urinary catheter was left in place for $48 \mathrm{~h}$; therefore, a too-short duration of catheterisation should not have contributed to rUO. The protocol of the present study, as well as the protocol of the prospective study by Zezza et $\mathrm{al}_{1}^{7}$ did not include $\alpha$-sympatholytic drugs, which were part of the treatment protocol in the mentioned prospective study on pentosan polysulfate,,$^{20}$ and used in $84-97 \%$ of affected cats in the mentioned retrospective studies. This could contribute to higher rates of rUO in the present study. Most of the rUO occurred early after removal of the indwelling urinary catheter (day 2 or day 3 ) only shortly after the start of the study medication. This might be too early to expect an optimal effect of the treatment. In addition, a significantly higher number of cats in the meloxicam group had previous episodes of FLUTD and five cats had already suffered from three or more clinical episodes, whereas no cat in the placebo group had had more than two episodes in the past. Therefore, a higher number of cats with a more severe and more chronic form of FIC in the meloxicam group might have obscured the beneficial effects of meloxicam in the present study.

During hospitalisation, no difference in pain on abdominal palpation was identified. One limitation of the study is that pain was not assessed using a standardised pain-scoring system. It is possible that an effect of meloxicam would have been identified with a more precise pain assessment. It could also be that the effect of meloxicam for this visceral pain is not strong enough and that these cats need more potent drugs such as morphine derivatives. It is also possible that the dose of meloxicam used in the present study $(0.1 \mathrm{mg} / \mathrm{kg}$ day $1,0.05 \mathrm{mg} / \mathrm{kg}$ day 2$)$ was not high enough. The used dosage on day 1 was lower than dosages recommended for cats for surgeryassociated pain, ${ }^{21}$ but doses on days $2-5$ were in agreement with the recommendation for oral administration of 
Table 6 Results of the questionnaire for days 1-5 after discharge from the hospital

\begin{tabular}{|c|c|c|c|c|c|c|}
\hline & Day & Meloxicam & Placebo & $\begin{array}{l}P \text { value } \\
\text { meloxicam vs } \\
\text { placebo }\end{array}$ & $\begin{array}{l}P \text { value meloxicam } \\
\text { day } 1 \text { vs } 2,3,4 \\
\text { and } 5\end{array}$ & $\begin{array}{l}P \text { value placebo } \\
\text { day } 1 \text { vs } 2,3,4 \\
\text { and } 5\end{array}$ \\
\hline \multirow{5}{*}{$\begin{array}{l}\text { General } \\
\text { demeanour }\end{array}$} & 1 & $4.10 \pm 2.30$ & $3.35 \pm 2.39$ & NS & & \\
\hline & 2 & $3.36 \pm 2.14$ & $3.51 \pm 2.52$ & NS & NS & NS \\
\hline & 3 & $2.46 \pm 2.27$ & $2.22 \pm 2.17$ & NS & NS & NS \\
\hline & 4 & $1.94 \pm 2.01$ & $2.22 \pm 2.17$ & NS & NS & NS \\
\hline & 5 & $1.84 \pm 1.80$ & $2.24 \pm 2.43$ & NS & NS & NS \\
\hline \multirow[t]{5}{*}{ Food intake } & 1 & $3.74 \pm 2.35$ & $4.39 \pm 3.05$ & NS & & \\
\hline & 2 & $3.90 \pm 2.86$ & $4.32 \pm 3.08$ & NS & NS & NS \\
\hline & 3 & $3.27 \pm 2.51$ & $3.02 \pm 3.07$ & NS & NS & NS \\
\hline & 4 & $2.35 \pm 2.15$ & $2.08 \pm 2.46$ & NS & NS & NS \\
\hline & 5 & $2.59 \pm 2.44$ & $2.32 \pm 2.50$ & NS & NS & NS \\
\hline \multirow[t]{5}{*}{ Painful voiding } & 1 & $1.78 \pm 2.88$ & $2.29 \pm 3.19$ & & & \\
\hline & 2 & $2.64 \pm 3.54$ & $1.68 \pm 2.72$ & NS & NS & NS \\
\hline & 3 & $2.14 \pm 3.22$ & $1.87 \pm 2.69$ & NS & NS & NS \\
\hline & 4 & $1.14 \pm 2.63$ & $1.24 \pm 2.65$ & NS & NS & NS \\
\hline & 5 & $1.24 \pm 2.63$ & $1.43 \pm 2.64$ & NS & NS & NS \\
\hline \multirow[t]{5}{*}{ Stranguria } & 1 & $2.37 \pm 2.45$ & $3.15 \pm 3.55$ & NS & & \\
\hline & 2 & $2.17 \pm 2.87$ & $2.85 \pm 3.02$ & NS & NS & NS \\
\hline & 3 & $1.43 \pm 2.36$ & $2.35 \pm 2.82$ & NS & NS & NS \\
\hline & 4 & $1.04 \pm 2.47$ & $1.97 \pm 3.01$ & NS & NS & NS \\
\hline & 5 & $1.04 \pm 2.45$ & $2.21 \pm 3.24$ & NS & NS & NS \\
\hline \multirow[t]{5}{*}{ Pollakiuria } & 1 & $3.41 \pm 3.24$ & $5.21 \pm 3.50$ & NS & & \\
\hline & 2 & $3.35 \pm 3.16$ & $3.31 \pm 2.92$ & NS & NS & NS \\
\hline & 3 & $3.32 \pm 3.45$ & $3.42 \pm 3.27$ & NS & NS & NS \\
\hline & 4 & $2.52 \pm 3.07$ & $2.78 \pm 3.23$ & NS & NS & NS \\
\hline & 5 & $1.59 \pm 2.65$ & $2.83 \pm 3.51$ & NS & NS & NS \\
\hline \multirow[t]{5}{*}{ Periuria } & 1 & $0.85 \pm 2.51$ & $1.23 \pm 2.28$ & NS & & \\
\hline & 2 & $1.32 \pm 2.81$ & $1.19 \pm 1.99$ & NS & NS & NS \\
\hline & 3 & $1.17 \pm 2.86$ & $2.01 \pm 2.66$ & NS & NS & NS \\
\hline & 4 & $1.19 \pm 2.72$ & $1.88 \pm 3.14$ & NS & NS & NS \\
\hline & 5 & $0.76 \pm 2.49$ & $2.83 \pm 3.16$ & NS & NS & NS \\
\hline
\end{tabular}

Owners assessed the parameters by markings on a $10 \mathrm{~cm}$ visual analogue scale. The left end of the scale was marked with findings expected in a normal cat such as normal food intake and no straining to urinate, whereas the right end of the scale was marked with abnormal findings such as no food intake, severe straining to urinate and frequently voiding outside the litter box. The distances from the left end of the scale to the marking were measured in $\mathrm{cm}$. For comparison of parameters between groups and within groups at different time points the Kruskal-Wallis test and Dunn's multiple comparison tests were applied. Significance was set at $P<0.05$

NS $=$ not significant

meloxicam.22 Even though meloxicam at this dose had no influence on the rate of rUO during the first week following obstruction and made no difference regarding clinical recovery between groups and over time, it is still possible that its analgesic and anti-inflammatory effect is of benefit when combined with other groups of analgesics such as morphine derivatives.

All NSAIDs, including meloxicam, should be used with caution in patients with impaired hepatic, cardiac or renal function, and haemorrhagic disorders. ${ }^{23}$ In addition, hypotension, hypovolaemia, sodium depletion, high dosages and inhalant anaesthesia are associated with a higher risk of renal toxicity. ${ }^{24}$ In the present study, the volume of
IV fluid therapy was adjusted based on the degree of dehydration, plasma electrolyte concentrations and the severity of postobstructive diuresis, and led to a normal volume and hydration status of the cats when entering the study. In all cats with azotaemia on admission, creatinine decreased and 29/37 had creatinine in the normal range or only mildly elevated creatinine on day 1 . A deficient volume status, azotaemia not responsive to fluid therapy or severe blood loss via the urine would have prohibited the use of meloxicam. Proteinuria assessed by dipstick, as well as haematuria assessed on urine sediment, improved significantly in both treatment groups over the study period. As the decrease in proteinuria 
paralleled the decrease in haematuria, proteinuria was assumed to be postrenal in origin. In rats, certain NSAIDs (ketoprofen and indomethacin) have been shown to have an ulcerogenic effect, ${ }^{25}$ and haemorrhagic cystitis in humans has been documented in association with tiaprofenic acid, indomethacin, diclofenac, ketoprofen, naproxen and piroxicam. ${ }^{26}$ As macroscopic and microscopic haematuria improved in both treatment groups, there was no hint for such a side effect of meloxicam in the present study.

\section{Conclusions}

The use of the non-steroidal anti-inflammatory drug meloxicam in cats with obstructive FIC did not influence the rate of rUO early after urinary catheter removal, and the hypothesis that anti-inflammatory therapy shortens the clinical episode and accelerates recovery could not be confirmed in this study population. The persistence of clinical signs for $>7$ days in most of the cats indicates that for recovery from episodes of obstructive FIC prolonged symptomatic treatment is warranted.

Conflict of interest The authors declared no potential conflicts of interest with respect to the research, authorship, and/ or publication of this article.

Funding This work was funded by Boehringer Ingelheim.

\section{References}

1 Lekcharoensuk C, Osborne CA and Lulich JP. Epidemiologic study of risk factors for lower urinary tract diseases in cats. J Am Vet Med Assoc 2001; 218: 1429-1435.

2 Lund EM, Armstrong PJ, Kirk CA, et al. Health status and population characteristics of dogs and cats examined at private veterinary practices in the United States. J Am Vet Med Assoc 1999; 214: 1336-1341.

3 Lee JA and Drobatz KJ. Characterization of the clinical characteristics, electrolytes, acid-base, and renal parameters in male cats with urethral obstruction. J Vet Emerg Crit Care 2003; 13: 227-233.

4 Gerber B, Boretti FS, Kley S, et al. Evaluation of clinical signs and causes of lower urinary tract disease in European cats. J Small Anim Pract 2005; 46: 571-577.

5 Saevik BK, Trangerud C, Ottesen N, et al. Causes of lower urinary tract disease in Norwegian cats. J Feline Med Surg 2011; 13: 410-417.

6 Segev G, Livne H, Ranen E, et al. Urethral obstruction in cats: predisposing factors, clinical, clinicopathological characteristics and prognosis. J Feline Med Surg 2011; 13: 101-108.

7 Zezza L, Reusch CE and Gerber B. Intravesical application of lidocaine and sodium bicarbonate in the treatment of obstructive idiopathic lower urinary tract disease in cats. J Vet Intern Med 2012; 26: 526-531.
8 Bovee KC, Reif JS, Maguire TG, et al. Recurrence of feline urethral obstruction. J Am Vet Med Assoc 1979; 174: 93-96.

9 Gerber B, Eichenberger S and Reusch CE. Guarded longterm prognosis in male cats with urethral obstruction. J Feline Med Surg 2008; 10: 16-23.

10 Eisenberg BW, Waldrop JE, Allen SE, et al. Evaluation of risk factors associated with recurrent obstruction in cats treated medically for urethral obstruction. J Am Vet Med Assoc 2013; 243: 1140-1146.

11 Buffington CAT, Chew DJ and Woodworth BE. Animal model of human disease - feline interstitial cystitis. Comp Path Bull 1997; 29: 3-6.

12 Osborne CA, Kruger JM, Lulich JP, et al. Prednisolone therapy of idiopathic feline lower urinary tract disease: a double-blind clinical study. Vet Clin North Am Small Anim Pract 1996; 26: 563-569.

13 Wallius BM and Tidholm AE. Use of pentosan polysulphate in cats with idiopathic, non-obstructive lower urinary tract disease: a double-blind, randomised, placebo-controlled trial. J Feline Med Surg 2009; 11: 409-412.

14 Hetrick PF and Davidow EB. Initial treatment factors associated with feline urethral obstruction recurrence rate: 192 cases (2004-2010). J Am Vet Med Assoc 2013; 243: 512-519.

15 Claria J and Romano M. Pharmacological intervention of cyclooxygenase-2 and 5-lipoxygenase pathways. Impact on inflammation and cancer. Curr Pharm Des 2005; 11:3431-3447.

16 Crofford LJ. COX-1 and COX-2 tissue expression: implications and predictions. J Rheumatol Suppl 1997; 49: 15-19.

17 Ito S, Okuda-Ashitaka E and Minami T. Central and peripheral roles of prostaglandins in pain and their interactions with novel neuropeptides nociceptin and nocistatin. Neurosci Res 2001; 41: 299-332.

18 Warner TD and Mitchell JA. Cyclooxygenases: new forms, new inhibitors, and lessons from the clinic. FASEB J 2004; 18: 790-804.

19 Bradley AM and Lappin MR. Intravesical glycosaminoglycans for obstructive feline idiopathic cystitis: a pilot study. J Feline Med Surg 2014; 16: 504-506.

20 Delille M, Frohlich L, Muller RS, et al. Efficacy of intravesical pentosan polysulfate sodium in cats with obstructive feline idiopathic cystitis. J Feline Med Surg 2016; 18: 492500.

21 Robertson SA. Managing pain in feline patients. Vet Clin North Am Small Anim Pract 2005; 35: 129-146.

22 Sparkes AH, Heiene R, Lascelles BD, et al. ISFM and AAFP consensus guidelines: long-term use of NSAIDs in cats. J Feline Med Surg 2010; 12: 521-538.

23 Plumb DC. Plumb's veterinary drug handbook. 8th ed. Ames, IA: Wiley Blackwell, 2015.

24 KuKanich B, Bidgood T and Knesl O. Clinical pharmacology of non-steroidal anti-inflammatory drugs in dogs. Vet Anaesth Analg 2012; 39: 69-90.

25 Takagi-Matsumoto $\mathrm{H}, \mathrm{Ng} \mathrm{B}$, Tsukimi Y, et al. Effects of NSAIDs on bladder function in normal and cystitis rats: a comparison study of aspirin, indomethacin, and ketoprofen. J Pharmacol Sci 2004; 95: 458-465.

26 Ghose K. Cystitis and non-steroidal anti-inflammatory drugs: an incidental association or an adverse effect? $N \mathrm{Z}$ Med J 1993; 106: 501-503. 